\title{
THE IMPACT OF WOLF REINTRODUCTION ON THE ForAGING EFFICIENCY OF ELK AND BISON
}

\author{
JOHN W. LAUNDRÉ $\downarrow$ DEPARTMENT OF BIOLOGICAL SCIENCES \\ IDAHO STATE UNIVERSITY $\downarrow$ POCATELLO
}

\begin{abstract}
$\downarrow \quad$ INTRODUCTION
More and more, evidence indicates that nonlethal interactions between large mammalian ungulates and the predators that feed on them may play significant roles in ungulate population dynamics. Although predators such as wolves and mountain lions directly impact large ungulates like elk (Cervus elaphus) when they kill individuals, the fact that they scare their prey may actually have a greater long term impact on the population (Kotler and Hoyt 1989, Brown 1992, Brown and Alkon 1990 Brown et al. 1999). In response to predation risk, foraging animals are found balancing conflicting demands for food and safety. Research indicates they do this by two principal means: 1) when faced with higher predation risk, prey individuals will reduce feeding effort and/or increase vigilance compared to areas of lower risk (Sih 1980, Lima and Dill 1990), 2) they alter their use of habitat types to help reduce this predation risk. The major result is that reduced feeding efforts or selection of safer but possibly less productive habitat lead to a third prediction of a poorer quality diet as animals seek out safer areas but with likely lower quality forage.
\end{abstract}

The reintroduction of wolves in Yellowstone National Parks offered a unique opportunity to test the impact of wolves on the feeding efficiency of elk and bison. After the wolves were reintroduced into Yellowstone Park in the spring of 1995, they quickly established themselves in specific locations, specifically in the Lamar Valley in the north end of the Park. This allowed us to collect data on areas with and without wolves for the first few years after their release. Additionally, as wolves have expanded their range in the Park, this has also provided an excellent opportunity to compare data on animals from the same areas before and after wolves have arrived. These comparisons then, would provide a critical test of the predictions that large predators can have a major non-lethal impact on their prey.

To test these predictions, in 1996 we began a study of the foraging patterns of elk and bison in Yellowstone National Park. Here we report the results of the first four years of this study.

\section{$\downarrow \quad$ METHODS}

Yellowstone National Park is an extensive area of varied forested and open grassland habitat. Elk and bison can be readily observed in most areas of the Park along the several roads that connect the various tourist attractions. The wolves adjusted to the presence of people and were also quite visible from the road. This has afforded us ample opportunities to observe elk and bison in the various areas of the Yellowstone. During 1996 and 1997 most places outside of the Lamar valley could be considered wolf free areas. However, this situation changed and by 1998 Swan Lake Flat had wolf activity. Data collection in this area the last two years provided a unique opportunity to compare with the preliminary data from 1996-97.

For sampling the amount of time spent feeding vs surveying, we make observations from existing roads and with the aid of spotting scopes. A given observation bout consists of first selecting an elk or bison that is actively feeding. The chosen 
animal is then observed until it stops feeding and lies down for a maximum of a half an hour. If an animal lies down less than twenty minutes after initiation of observations, those data are discarded. During that time, it is watched continuously and the start and ending times of feeding bouts are recorded. A feeding bout is classified as an animal having its head bent down in a position preventing it from looking around. When an animal has its head held up between bouts it is classified based on whether the animal is standing and looking around or whether it is moving to another feeding spot.

Data collection was limited to adult animals and target minimal sample sizes per year were as follows: 20 males, 20 females with young and, 20 females without young in each of the sample areas. Division into social class allows an additional comparison of feeding efficiency among these social groups. Animals selected for observation are within similar group sizes. This reduces variability in surveillance times that might result from different levels of security felt in different size groups.

The data analyzed were percent time spent feeding or surveying during the observation block. Percents were used to enable comparisons of unequal time blocks. Observation blocks were limited to those greater than 20 minutes to reduce the high variability of percentages for small time intervals. This allowed statistical comparisons of the arcsine transformed data of percent time animals spend feeding vs surveillance among the appropriate areas. The null hypothesis was that there is no difference in percent time feeding or surveying between areas and among the social categories, e.g. males vs females with calves vs females without calves. The statistical test used was a three factor analysis of variance. The three factors were percent feeding time (or surveillance time), social category, and sample year. There was a minimum of 20 replicates per cell. With this sample size, there should be adequate power to test the hypothesis.

To test if elk and bison are shifting in habitat use (\#2), we sampled the number of fecal pellet groups (elk) and fecal droppings (bison) in a $10 \mathrm{~m}^{2}$ sample area. We randomly select 10 transect lines within a given area that start $50 \mathrm{~m}$ into the forest and extend $500 \mathrm{~m}$ into the open. We sampled every $50 \mathrm{~m}$ along the transects. These data provided an estimate of relative use of the different distances from the forest to the open meadow. We hypothesized that predation risk is higher further out into the open meadow (wolves run their prey down and thus they would be more vulnerable in open areas). Thus, it is predicted that where wolves are, we would see a significant decrease in pellet groups or droppings as we go further into the open meadow. The statistical hypothesis tested is that the slope of the regression line of fecal density to distance from forest edge is 0.0. Rejection of this hypothesis will support the biological hypothesis of habitat shifts.

To test the prediction (\#3) that resulting shifts in foraging effort (prediction \#1) and location (prediction \#2) result in poorer diet quality, we analyzed fecal nitrogen, phosphorous, and protein levels between the two areas. These parameters have been used by others as estimates of diet quality in ungulates (Osborne and Jenks 1998) and should enable assessment of diet quality of elk and bison in wolf and non-wolf areas. The statistical hypothesis tested was that animals from both areas will have equal diet quality (fecal nitrogen, phosphorous, protein). Rejection of this hypothesis will support the biological hypothesis of differences in diet quality.

Scats for testing diet quality are collected when we count the number of fecal samples within the $10 \mathrm{~m}^{2}$ sample plots set up to assess habitat use. Previous tests have shown that 20 samples for each species in each area are adequate to estimate the levels of fecal nitrogen, phosphorus, and protein. Collected scats are sent to a commercial analysis lab for the determination of fecal nitrogen, phosphorous, and protein.

\section{$\downarrow \quad$ RESUlTS}

\section{Field effort}

During 1996 to 1999 , we collected data on approximately 600 feeding bouts of elk from areas exposed to wolf predation and unexposed areas. In 1998 and 1999, we also collected data on approximately 250 feeding bouts of bison. We have also collected over 250 fecal samples of elk and bison from areas with and without wolves.

\section{$\uparrow \quad$ PREliminary RESUlts}

For elk, we just finished our fifth year of data collection on vigilance and have completed the analysis of the data from the first four years. Figure 1 presents our analysis of the percent time animals in the various social classes spent surveying for the four years. These results indicate that females with and without calves in areas where there are wolves do spend significantly more time surveying and less time 
foraging than their counterparts in unexposed areas. Additionally, the percent of time spent surveying for females with calves seems to be greater in both areas than for females without calves. There was no difference seen for males. Data for 1997 for females with and without calves showed that animals in exposed areas spent more time surveying than last year. Females with calves were spending close to $50 \%$ of their time surveying as opposed to $25 \%$ in unexposed areas. Analysis of the 1998 data indicate a similar pattern, however, with a substantial increase in vigilance for females with calves in non-wolf areas. This increase could be related to the expanding presence of wolves. Our analysis of the 1999 data support this idea.

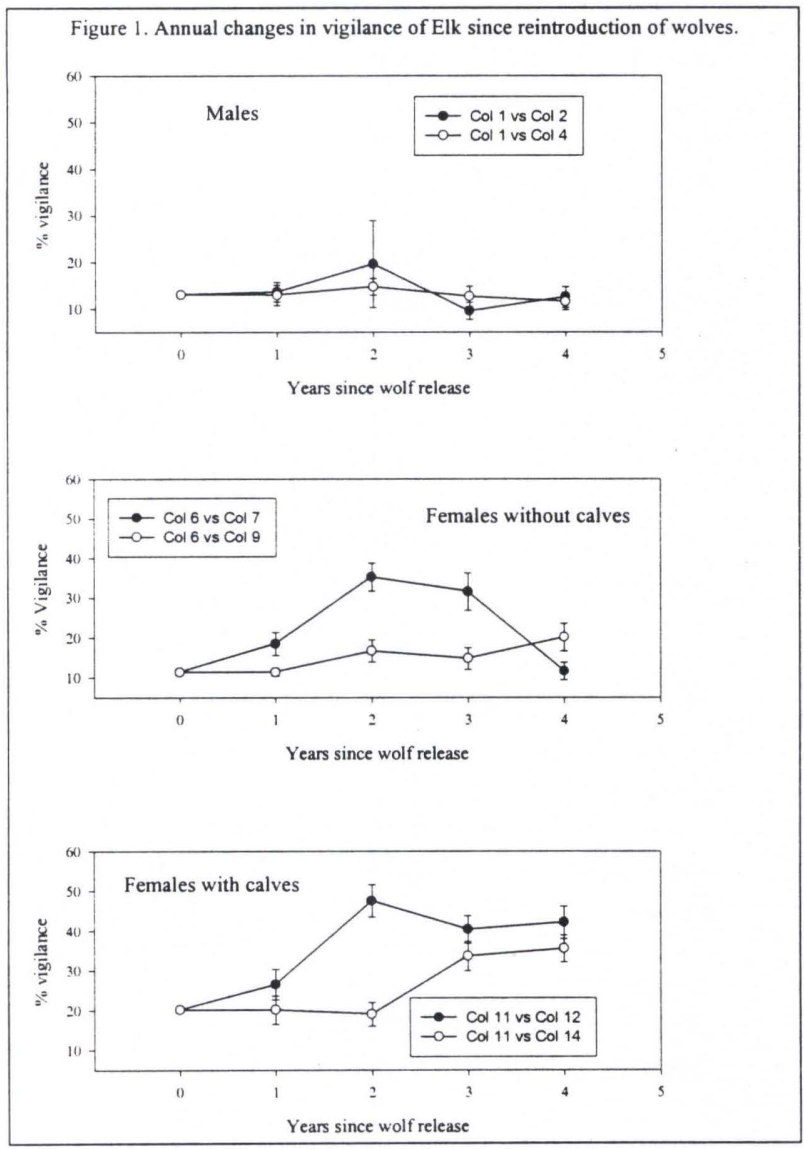

We finished our first year of data collection on bison in 1998. Analysis of these data indicate a similar trend for bison (Fig. 2). Female bison with calves exhibited the highest level of vigilance, even in the absence of wolves. Also, both female groups exhibited an increase in vigilance when exposed to wolves. Our data from 1999, however, indicate major declines in vigilance for both female social groups (Fig. 2).

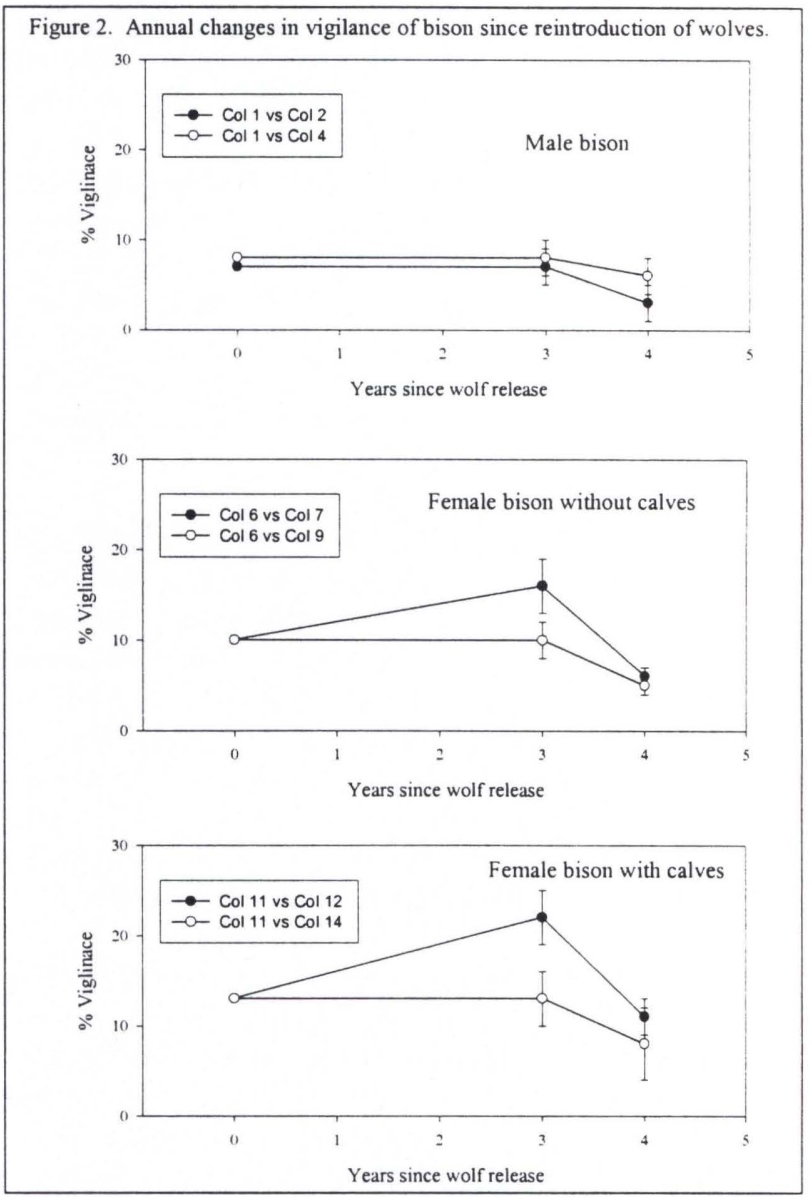

Regarding the habitat use, as seen in Figure $3 \mathrm{a}$, the number of pellet groups per $10 \mathrm{~m}^{2}$ in Lamar Valley significantly decreased as we moved further out into the open. This pattern was not seen in the other non-wolf areas. The same pattern was seen in 1999, however, there were fewer pellet groups found in Lamar Valley overall (Fig. 3b). No significant relation between distance from forest and number of bison droppings was seen in either year (Fig. 4).

We sent approximately 100 scat samples of elk and bison from wolf and non-wolf areas to be analyzed. For elk, in areas with wolves, percent fecal nitrogen $(1.6 \% \mathrm{SE}=0.40)$, protein $(9.8 \%, \mathrm{SE}=$ $0.57)$, and phosphorus $(2,097 \mathrm{mg} / \mathrm{kg}, \mathrm{SE}=258.6)$ were significantly less than non-wolf areas $(\mathrm{N}=$ $2.1 \%, \mathrm{SE}=0.68$; Protein $=13.1 \%, \mathrm{SE}=0.67, \mathrm{P}=$ $4,110 \mathrm{mg} / \mathrm{kg}, \mathrm{SE}=532.2$ ). No difference was seen for bison. The data from 1999 have yet to be analyzed but should provide further insights into the impact of the wolf reintroduction on diet quality in elk and bison. 


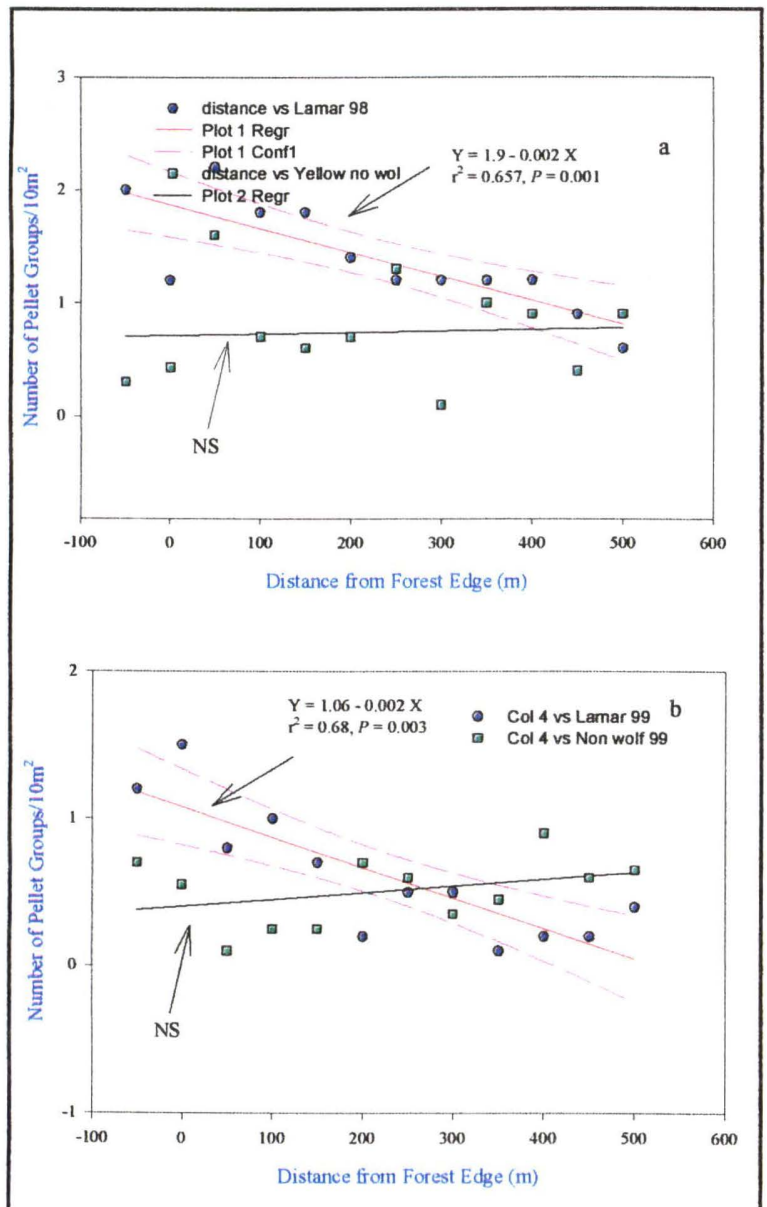

Figure 3. Number of pellet groups (elk) per $10 \mathrm{~m}^{2}$ sample plots located at $50 \mathrm{~m}$ intervals. Plots started $50 \mathrm{~m}$ within the forest and were located every $50 \mathrm{~m}$ up to $500 \mathrm{~m}$ into open Figure $3 \mathrm{a}$ is of data from 1998 and $3 \mathrm{~b}$ is of data from 1999 .

All these results so far support the hypotheses that wolves are having an impact on the foraging efficiency of elk and somewhat of an effect (behavioral) on bison. However, that impact seems to be changing with time. When we add the data from this year (2000), we will have a clearer picture of what the non lethal effects of the wolf reintroduction has had on elk and bison in Yellowstone National Park.
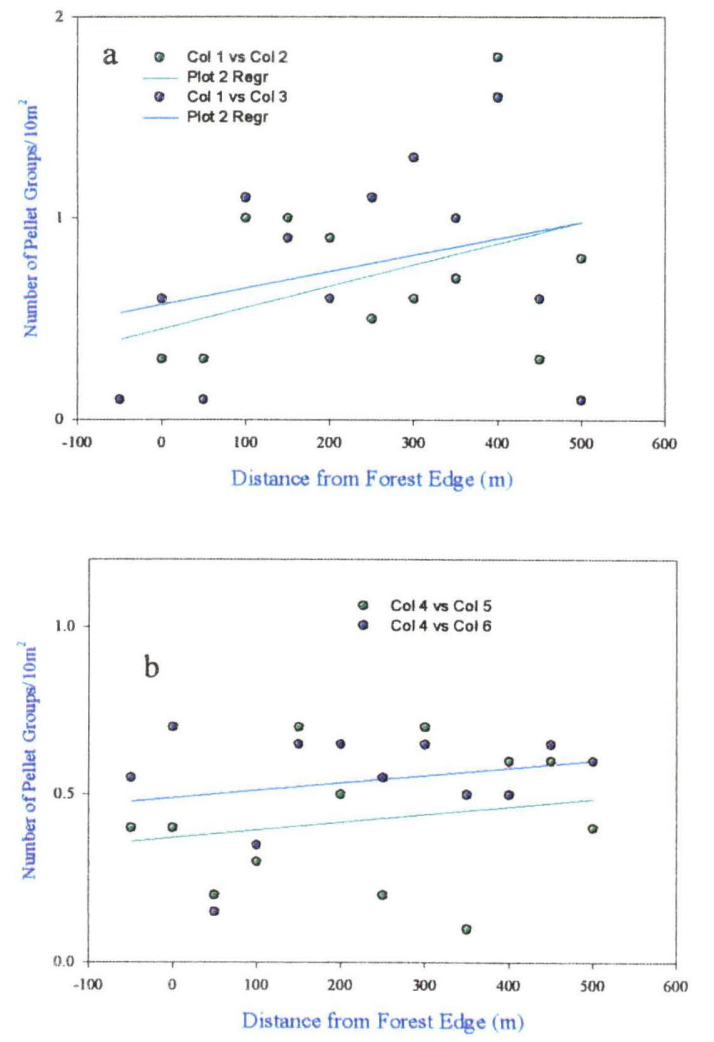

Figure 4. Number of bison flops per $10 \mathrm{~m}^{2}$ sample plots for 1998 (a) and 1999 (b) located at $50 \mathrm{~m}$ intervals Figure 4. Number of bison flops per $10 \mathrm{~m}^{2}$ sample plots for 1998 (a) and 1999 (b) located at $50 \mathrm{~m}$ intervals
Plots started $50 \mathrm{~m}$ within the forest and were located every $50 \mathrm{~m}$ up $10500 \mathrm{~m}$ into open.

\section{$\checkmark$ REFERENCES CITED}

Brown, J.S. 1992. Patch use under predation risk: I Models and predictions. Ann. Zool. Fenn. 29:301-309.

Brown, J.S. and P.U. Alkon. 1990. Testing values of crested porcupine habitats by experimental food patches. Oecologia 83:512-518.

Brown, J.S., J. W. Laundré, and M.K. Gurung. 1999. The ecology of fear: Optimal foraging, game theory, and trophic interactions. J. Mammalogy, 80:385-399. 
Kotler, B.P. and R.D. Hoyt. 1989. Predation and competition: the interaction of two types of species interactions. Oikos 54:256-260.

Lima S.L. and L.M Dill. 1990. Behavioral decisions made under the risk of predation: a review and prospectus. Can. J. Zool. 68:619-640.

Osborne, R.G. and J.A. Jenks. 1998. Assessing dietary quality of white-tailed deer using fecal indices: effects of supplemental feeding and area. J. Mammal. 79:437-447.

Sih, A. 1980. Optimal behavior: can foragers balance two conflicting demands? Science 210:1041-1043. 